\title{
THERAPY OF DIGNITY: STRATEGY FOR THE CONSTRUCTION OF A LEGACY AT THE END OF LIFE
}

Natália Novaes Pavani Araújo1, Marcella Tardeli Esteves Angelloni Santana1', Ricardo Caponero1, Joice Aline Klein'1, Ana Lúcia Coradazzi', Danilo Augusto Mendonça Faleiros

'Universidade de São Paulo - São Paulo (SP), Brazil.

Introduction: Dignity Therapy is a tool proposed by Chochinov et al. (2005) that aims to build a legacy through a letter written with the patient in palliative care, which can be delivered to loved ones in life or after his death. The multidisciplinary team can use this technique in their practice, not only with the purpose of promoting patient care while preserving their dignity, but also offering a holistic attention to the patient / family care unit. Objective: to report a patient experience based on Dignity Therapy intervention. Method: This is a descriptive, case study. The activity was developed in a large private hospital, in São Paulo, in February 2018. The sample consisted of a 53-year-old patient with advanced malignant neoplasm at the end of life. The intervention was conducted in two meetings with the formulation of 17 letters dictated and signed by the patient and written by the chaplain of the service in the period that preceded her palliative sedation. All the letters were destined to the daughter in order to open them over the next few years. Result: After the preparation of the letters, the patient's psychosocial suffering was improved, which consisted of no longer participating in the main moments of the daughter's life due to her impending death, as well as the possibility of retrieving memories and projecting expectations, manifesting hope and become, symbolically, a participant in the daughter's future. Considerations: It is considered that the team's performance in an interdisciplinary approach, and based on the therapy of dignity, contributed with the care of the intense psychosocial suffering experienced by the patient in the terminal phase of the disease. 